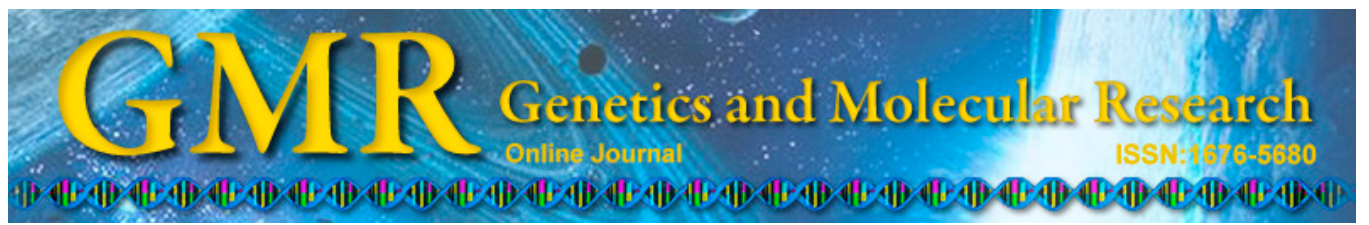

\title{
Relationship between clinicopathological features and HIF-2 $\alpha$ in gastric adenocarcinoma
}

\author{
N. Li ${ }^{1 *}$, H.X. Wang ${ }^{2 *}$, C. Qin ${ }^{1}$, X.H. Wang ${ }^{1}$ and F.Y. Han ${ }^{1}$ \\ ${ }^{1}$ Department of Pathology, Xinxiang Medical University, Xinxiang, China \\ ${ }^{2}$ Department of Clinical Immunology, Xinxiang Medical University, \\ Xinxiang, China \\ *These authors contributed equally to this study. \\ Corresponding author: N. Li \\ E-mail: lina@xxmu.edu.cn
}

Genet. Mol. Res. 14 (1): 1404-1413 (2015)

Received January 3, 2014

Accepted May 11, 2014

Published February 13, 2015

DOI http://dx.doi.org/10.4238/2015.February.13.19

\begin{abstract}
Hypoxia influences tumor growth by inducing angiogenesis and genetic alterations. Hypoxia-inducible factor- $2 \alpha$ (HIF-2 $\alpha$ ) plays an essential role in oxygen homeostasis. Expression of HIF- $2 \alpha$-inducible genes is associated with tumor progression. In this study, we investigated this correlation immunohistochemically and using quantitative reverse transcription-polymerase chain reaction to examine various clinical and pathological features in 55 specimens of gastric cancer and 40 specimens of normal gastric tissue. The HIF- $2 \alpha$ mRNA expression level and protein expression were significantly higher in gastric cancer tissue samples than in adjacent tissue samples. The positive rates of HIF- $2 \alpha$, matrix metalloprotease-9 (MMP-9), and vascular endothelial growth factor (VEGF) protein were $63.6 \%(35 / 55), 80.0 \%(44 / 55)$, and $65.5 \%$ $(36 / 55)$ in gastric cancer tissue specimens, respectively. These values were significantly higher than those in normal gastric tissue samples $(\mathrm{P}=0.001, \mathrm{P}=0.000$, and $\mathrm{P}=0.007$, respectively). HIF$2 \alpha$ and MMP-9 were significantly correlated with primary tumor size $(\mathrm{P}=0.0065$ and $\mathrm{P}=0.036$, respectively) and invasion depth
\end{abstract}


$(\mathrm{P}=0.012$ and $\mathrm{P}=0.008$, respectively). HIF- $2 \alpha$ and VEGF were significantly correlated with lymph node involvement $(\mathrm{P}=0.030$ and $\mathrm{P}=0.016$, respectively). Expression of HIF- $2 \alpha$ was positively correlated with the expression of VEGF and MMP-9 ( $\mathrm{P}=0.036$ and $\mathrm{P}=0.000$, respectively). These results suggest that HIF- $2 \alpha$ is involved in gastric carcinogenesis and disease progression and is a potential therapeutic target for gastric carcinoma.

Key words: Clinicopathological characteristics; Gastric cancer; Hypoxia-inducible factor-2 $\alpha$; Prognosis

\section{INTRODUCTION}

In gastric cancer, lymph node metastasis and distant metastasis have been established as standard prognostic factors for relapse-free and overall survival. Angiogenesis is a crucial mediator of tumor progression. As tumors expand, diffusion distances from the existing vascular supply increase, resulting in hypoxia (Bohensky et al., 2009). Hypoxia-inducible factors (HIFs) drive the survival and development of cancer cells by inducing cellular adaptations as well as angiogenesis and genetic alterations that promote tumor cell survival, proliferation, invasion, and disease progression. As a result, hypoxia and HIFs are associated with poor prognosis in many tumor types (Mole et al., 2009; Mardilovich and Shaw, 2009; Trisciuogglio et al., 2010; Mazumdar et al., 2010; Burrows et al., 2011). Hypoxia-inducible factor-1 $\alpha$ (HIF-1 $\alpha$ ) has been associated with poor prognosis in a variety of cancers, including uterine, breast, and non-small cell lung cancer, as well as poor response to cancer therapies (Rankin and Giaccia, 2008; Bohensky et al., 2009; Mole et al., 2009; Burrows et al., 2011). Over 100 HIF target genes have been identified. HIF promotes tumor cell survival and progression by regulating multiple genes, including those involved in angiogenesis [vascular endothelial growth factor (VEGF)], anaerobic metabolism (GLUT1), control of intracellular pH (CA-9), regulation of the cell cycle, DNA damage response, proliferation and apoptosis (p21 and p27), extracellular matrix remodeling and cell migration (lysyl oxidase), and matrix-metalloprotease-1 and -9 (MMP-1 and -9) (Jiang et al., 2003; Meade et al., 2007; Copple et al., 2010; Liu et al., 2011). The HIF pathway may be a novel therapeutic target for reducing local tumor growth, metastatic burden, and resistance to chemo/radiotherapy. However, little is known regarding the role of HIF- $2 \alpha$ in solid tumors. Current data suggest that the response to hypoxia is largely mediated by HIF- $1 \alpha$ in endothelial and breast cancer cells but by HIF- $2 \alpha$ in renal carcinoma cells. HIF- $2 \alpha$ overexpression is important in the development of renal carcinoma in patients with Von Hippel Lindau syndrome. In neuroblastomas, expression of HIF-2 $\alpha$ was found to be associated with more aggressive disease. However, other studies in glioblastomas suggested that overexpression of HIF- $2 \alpha$ enhances angiogenesis but reduces tumor growth. Although the role of HIF- $1 \alpha$ in gastric cancer has been characterized, the relationship between HIF- $2 \alpha$ expression, its clinicopathological significance, and prognosis in gastric carcinogenesis is not well understood. In this study, we used immunohistochemistry to examine the expressions of HIF-2 $\alpha$, MMP-9, and VEGF protein in surgical gastric cancer specimens. In addition, we examined the mRNA expression of $H I F-2 \alpha$ to evaluate the clinicopathological significance and relationship between each factor. 


\section{MATERIAL AND METHODS}

\section{Patients and tumor tissue samples}

Fifty-five gastric cancer tissue samples and 40 adjacent tissue samples were obtained from the First Affiliated Hospitals of Xinxiang Medical University between January 2010 and December 2011, snap-frozen, and stored at $-70^{\circ} \mathrm{C}$. None of the patients had received radiotherapy or chemotherapy prior to surgery. Both tumors were confirmed by pathological examination. All tissue samples were fixed in $10 \%$ formalin and embedded in paraffin, and consecutive 4- $\mu \mathrm{m}$ sections were cut. Tissue specimens were examined for the following characteristics: depth of tumor invasion, presence of lymph node involvement, macroscopic and histological type, tumor size, and tumor node metastasis stage. Staging of gastric cancer and clinicopathological factors utilized in this study were based on the 6th edition of the American Joint Committee on Cancer's Cancer Staging Manual. Institutional Review Board approvals were obtained through the First Affiliated Hospitals of Xinxiang Medical University. Clinical pathological characteristics of the 55 gastric cancer patients are listed in Table 1.

\begin{tabular}{|c|c|c|}
\hline Characteristics & No. of patients & $\%$ \\
\hline Total number of patients & 55 & 100.0 \\
\hline \multicolumn{3}{|l|}{ Gender } \\
\hline Male & 35 & 63.6 \\
\hline Female & 20 & 36.4 \\
\hline Age at surgery (years) & $59(28-84)$ & \\
\hline$<60$ & 24 & 43.6 \\
\hline$\geq 60$ & 31 & 56.4 \\
\hline \multicolumn{3}{|l|}{ Tumor size } \\
\hline$<4$ & 28 & 50.9 \\
\hline$\geq 4$ & 27 & 49.1 \\
\hline \multicolumn{3}{|c|}{ Depth of primary tumor invasion } \\
\hline $\mathrm{T} 1+\mathrm{T} 2$ & 21 & 38.2 \\
\hline $\mathrm{T} 3+\mathrm{T} 4$ & 34 & 61.8 \\
\hline \multicolumn{3}{|l|}{ Tumor location } \\
\hline Diffuse & 16 & 29.1 \\
\hline Mixed & 15 & 27.3 \\
\hline Undetermined & 24 & 43.6 \\
\hline \multicolumn{3}{|c|}{ Status of lymph node metastasis } \\
\hline Negative & 20 & 36.4 \\
\hline Positive & 35 & 63.6 \\
\hline \multicolumn{3}{|l|}{ TNM stage } \\
\hline I & 16 & 29.1 \\
\hline II & 12 & 21.8 \\
\hline III & 12 & 21.8 \\
\hline IV & 15 & 27.3 \\
\hline
\end{tabular}

\section{Immunohistochemical analysis}

The best tissue section for immunohistochemistry was selected. Sections were deparaffinized and rehydrated using graded ethanol, and then endogenous peroxidase was inhibited using $0.3 \%$ hydrogen peroxide. For antigen retrieval, slides were boiled in $1 \mathrm{mM}$ ethylenediaminetetraacetic acid, $\mathrm{pH} 8.0$, for $15 \mathrm{~min}$ in a microwave oven. Tissue sections were stained 
with rabbit polyclonal antibody against human HIF-2 $\alpha$ (Santa Cruz Biotechnology, Santa Cruz, CA, USA) at 1:100 dilution, rabbit polyclonal antibody against human MMP-9 (Santa Cruz Biotechnology) at 1:100 dilution, and rabbit polyclonal antibody against human VEGF (Jingmei Biotechnology, Beijing, China) at 1:100 dilution. All sections were incubated overnight with primary antibody at $4^{\circ} \mathrm{C}$. The sections were then treated with peroxidase using the labeled polymer method with peroxidase for $30 \mathrm{~min}$. Antibody binding was visualized using the Avidin Biotin Complex Elite Kit (Vector Laboratories, Burlingame, CA, USA) and 3,3-diaminobenzine according to manufacturer instructions. Sections were then counterstained with hematoxylin.

\section{Assessment of immunohistochemical staining in tissue sections}

Scoring was performed in a double-blinded manner by 2 investigators. Any disagreement was resolved by discussion to obtain final scores. Markers (HIF-2 $\alpha$, MMP-9, and VEGF) in the carcinogenesis study were scored using the same scoring system. The total immunostaining score was calculated as the sum of the percent positivity of stained tumor cells and staining intensity. The percent positivity was scored as " 0 " ( $<5 \%$, negative), " 1 " (5$25 \%$, sporadic), " 2 " ( $25-50 \%$, focal), or " 3 " ( $>50 \%$, diffuse). Staining intensity was scored as " 0 " (no staining), "1" (weakly stained), "2" (moderately stained), or "3" (strongly stained). Final expression scores were calculated using the value of percent positivity score $\mathrm{x}$ staining intensity score, which ranged from 0-9 as follows: "-" (score 0-3) and "+" (score > 3).

\section{Quantitative reverse transcription-polymerase chain reaction (PCR)}

Total RNA was isolated from tissue using Trizol (Gibco, Grand Island, NY, USA). After denaturation of RNA at $94^{\circ} \mathrm{C}$ for $5 \mathrm{~min}, 500 \mathrm{ng}$ RNA was reverse-transcribed into cDNA. The cDNA was then amplified using the following primers: HIF- $2 \alpha$ sense (5'-tgaaaacgagtccga agcc-3'), antisense (5'-gtggctgacttgaggttga-3'); MMP-9 sense (5'-aggagcggctctccaagaag-3'), antisense (5'-gggcactgcaggatgtcatag-3'); VEGF sense (5'-tacctccaccatgccaagtggt-3'), antisense (5'-aggacgcttgaagatgtac-3'). Duplex amplification was performed using a thermocycler for 30 cycles according to the following program: $1 \mathrm{~min}$ at $94^{\circ} \mathrm{C}, 30 \mathrm{~s}$ at $50^{\circ} \mathrm{C}$ (HIF-2 $\alpha$, MMP-9) or $55^{\circ} \mathrm{C}$ (VEGF), and $1 \mathrm{~min}$ at $72^{\circ} \mathrm{C}$. PCR products were separated by electrophoresis on a $1.5 \%$ agarose gel, with glyceraldehyde 3-phosphate dehydrogenase (580 bp) as an internal standard. PCR products were quantified using the Syngene gel analysis software (Cambridge, UK), and glyceraldehyde 3-phosphate dehydrogenase was used to normalize the data.

\section{Statistical analysis}

Data are reported as means \pm standard deviation. Correlation between categorical groups was evaluated using the $\chi^{2}$ test or the Fisher exact test. Analysis of variance was conducted and followed by independent-sample Student $t$-tests. Results were considered to be statistically significant when $\mathrm{P}<0.05$. Experiments were typically repeated independently 3 times unless indicated otherwise. All data were analyzed using the SPSS 13.0 software (SPSS, Inc., Chicago, IL, USA). 


\section{RESULTS}

\section{Immunohistochemical differences in HIF-2 $\alpha$, MMP-9, and VEGF between gastric cancer and normal gastric tissue specimens}

HIF-2 $\alpha$ was detected mainly in the epithelium of gastric cancer tissues and less frequently in normal gastric tissues. Strongly positive staining for HIF-2 $\alpha$ with a diffuse distribution pattern was identified throughout the mucosa in most adenocarcinomas (Figure 1A). In contrast, only weak positive staining for HIF-2 $\alpha$ was observed within the cytoplasm of a few normal gastric tissue specimens (Figure 1B). Positive HIF-2 $\alpha$ expression was detected in 35 of 55 gastric cancer tissue specimens and in 11 of 40 normal gastric tissue specimens. The positive ratio of HIF-2 $\alpha$ expression in gastric cancer tissue specimens was significantly higher than that in normal gastric tissue specimens $\left(\chi^{2}=12.108, \mathrm{P}=0.001\right)$ (Table 2$)$.
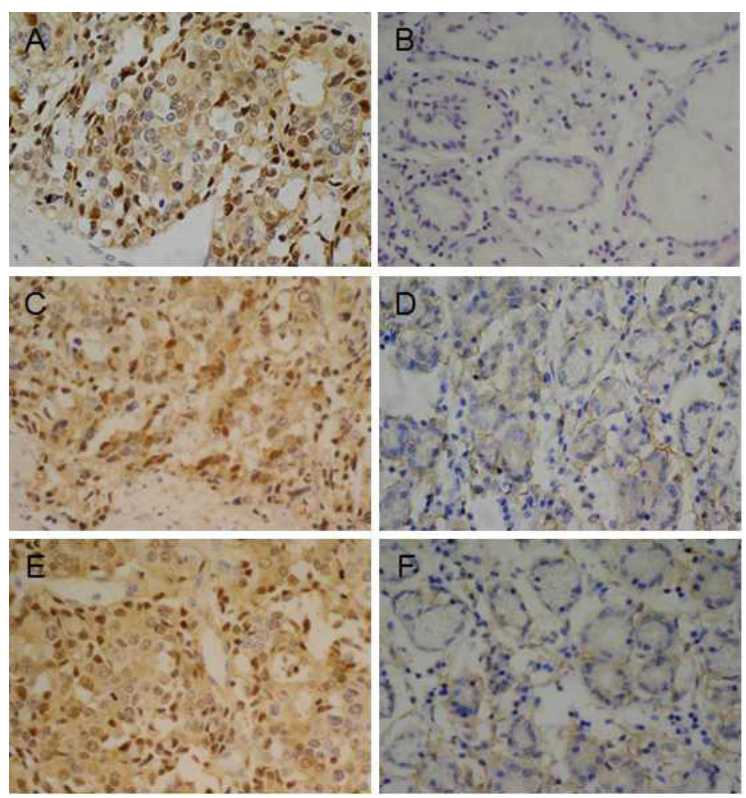

Figure 1. Immunohistochemical expression of HIF-2 $\alpha$, MMP-9, and VEGF proteins in gastric cancer tissues and normal gastric tissue. A. Positive expression of the HIF-2 $\alpha$ protein was present in both the cytoplasm and the nucleus of tumor cells. B. HIF-2 $\alpha$ protein expression was clearly absent in normal gastric epithelium. C. Positive expression of the MMP9 protein in gastric cancer tissues. Cytoplasms of tumor cells were diffusely stained brown. D. Weak expression of the MMP-9 protein was present in normal gastric epithelium. E. VEGF staining was present in the nucleus and cytoplasm of tumor cells. F. Weak expression of the VEGF protein was present in normal gastric epithelium (IHC, SP 200X).

Table 2. Expression of HIF-2 $\alpha$, MMP-9, and VEGF protein in gastric cancer tissue and normal gastric tissue specimens.

\begin{tabular}{|c|c|c|c|c|c|c|c|c|c|c|}
\hline \multirow[t]{2}{*}{ Group } & \multirow[t]{2}{*}{$\mathrm{N}$} & \multicolumn{3}{|c|}{ Expression of HIF- $2 \alpha$ protein } & \multicolumn{3}{|c|}{ Expression of MMP-9 protein } & \multicolumn{3}{|c|}{ Expression of VEGF protein } \\
\hline & & Negative & Positive & $\begin{array}{c}\text { Positive rate } \\
(\%)\end{array}$ & Negative & Positive & $\begin{array}{c}\text { Positive rate } \\
(\%)\end{array}$ & Negative & Positive & $\begin{array}{c}\text { Positive rate } \\
(\%)\end{array}$ \\
\hline Gastric cancer tissue & 55 & 20 & 35 & 63.6 & 11 & 44 & 80.0 & 19 & 36 & 65.5 \\
\hline Normal gastric tissue & 40 & 29 & 11 & 27.5 & 27 & 13 & 32.5 & 25 & 15 & 37.5 \\
\hline
\end{tabular}


MMP-9 was detected mainly in the epithelium of gastric cancer tissues and less frequently in normal gastric tissues. Strongly positive staining for MMP-9 was identified throughout the mucosa in most adenocarcinoma tissues (Figure 1C). In contrast, only weak positive staining for MMP-9 was observed within the cytoplasm of a few normal gastric tissue specimens (Figure 1D). Positive MMP-9 expression was detected in 44 of 55 gastric cancer tissue specimens and in 13 of 40 normal gastric tissue specimens. The positive ratio of MMP9 expression in gastric cancer tissue specimens was significantly higher than that in normal gastric tissue specimens $\left(\chi^{2}=21.771, \mathrm{P}=0.000\right.$; Table 2$)$.

VEGF was detected mainly in the epithelium of gastric cancer tissues and less frequently in normal gastric tissues. Strongly positive staining for VEGF was identified throughout the mucosa in most adenocarcinomas (Figure 1E). In contrast, only weak positive staining for VEGF was observed within the cytoplasm of a few normal gastric tissue specimens (Figure 1F). Positive VEGF expression was detected in 36 of 55 gastric cancer tissue specimens and in 15 of 40 normal gastric tissue specimens. The positive ratio of VEGF expression in gastric cancer tissue specimens was significantly higher than that in normal gastric tissue specimens $\left(\chi^{2}=7.278, \mathrm{P}=0.007\right.$; Table 2$)$.

\section{Expression of $H I F-2 \alpha$ mRNA in gastric cancer and adjacent tissue samples}

The positive expression rate and relative expression level of HIF-2 $\alpha$ mRNA in 55 gastric cancer tissue samples and 40 adjacent normal tissue samples were detected by quantitative reverse transcription-PCR. The positive expression rate and relative expression level of $H I F-2 \alpha$ mRNA were significantly higher in gastric cancer tissue samples than in adjacent normal tissue samples (Figure 2).
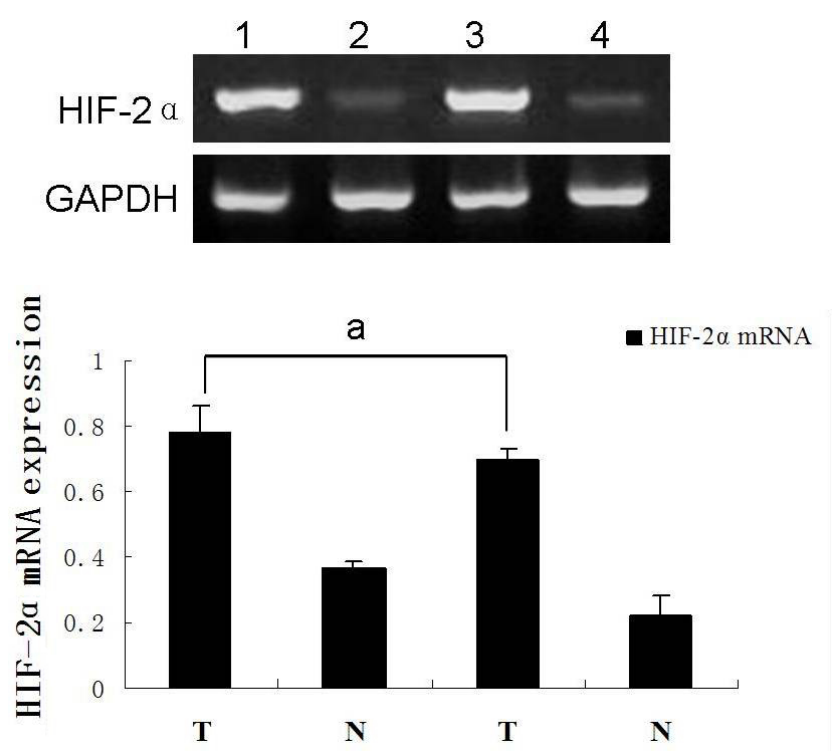

Figure 2. Reverse transcription-PCR analysis of $H I F-2 \alpha$ mRNA expression in gastric cancer tissues and normal gastric tissue. $H I F-2 \alpha$ mRNA was detected in paired tumor tissues (T) and surrounding non-tumor gastric tissues $(\mathrm{N})$ in 4 patients with gastric cancer. ${ }^{a} \mathrm{P}<0.05$ vs non-tumor gastric tissues. 


\section{Clinicopathological significance of HIF-2 $\alpha$, MMP-9, and VEGF protein expression in gastric cancer}

The correlations between HIF-2 $\alpha$, MMP-9, and VEGF protein expression and clinical pathological features of gastric cancer are shown in Table 3 . The positive rates of HIF- $2 \alpha$ and MMP-9 were 63.6 and $80.0 \%$, respectively. The VEGF overexpression rate was $65.5 \%$. HIF- $2 \alpha$ and MMP-9 were positively correlated with primary tumor size $(\mathrm{P}=0.006$ and $\mathrm{P}=$ 0.036 , respectively) and invasion depth $(\mathrm{P}=0.012$ and $\mathrm{P}=0.008$, respectively). HIF-2 $\alpha$ and VEGF were positively correlated with lymph node involvement $(\mathrm{P}=0.030$ and $\mathrm{P}=0.016$, respectively). However, HIF-2 $\alpha$ protein expression appeared to be unrelated to age and gender of patients, tumor location, and tumor node metastasis stage, indicating that additional studies are required to resolve these issues.

\begin{tabular}{|c|c|c|c|c|c|c|c|c|c|}
\hline \multirow[t]{2}{*}{ Characteristics } & \multicolumn{3}{|c|}{ Expression of protein HIF- $2 \alpha$} & \multicolumn{3}{|c|}{ Expression of protein MMP-9 } & \multicolumn{3}{|c|}{ Expression of protein VEGF } \\
\hline & $\begin{array}{l}\text { Negative } \\
(\mathrm{N}=20)\end{array}$ & $\begin{array}{l}\text { Positive } \\
(\mathrm{N}=35)\end{array}$ & $\mathrm{P}$ & $\begin{array}{l}\text { Negative } \\
(\mathrm{N}=11)\end{array}$ & $\begin{array}{l}\text { Positive } \\
(\mathrm{N}=44)\end{array}$ & $P$ & $\begin{array}{l}\text { Negative } \\
(\mathrm{N}=19)\end{array}$ & $\begin{array}{l}\text { Positive } \\
(\mathrm{N}=36)\end{array}$ & $\mathrm{P}$ \\
\hline \multicolumn{10}{|l|}{ Gender } \\
\hline Male & 11 & 24 & 0.314 & 6 & 29 & 0.483 & 13 & 22 & 0.592 \\
\hline Female & 9 & 11 & & 5 & 15 & & 6 & 14 & \\
\hline \multicolumn{10}{|c|}{ Age at surgery (years) } \\
\hline$<60$ & 10 & 14 & 0.472 & 6 & 18 & 0.415 & 6 & 18 & 0.190 \\
\hline$\geq 60$ & 10 & 21 & & 5 & 26 & & 13 & 18 & \\
\hline \multicolumn{10}{|l|}{ Tumor size } \\
\hline$<4$ & 12 & 8 & 0.006 & 7 & 13 & 0.036 & 8 & 12 & 0.520 \\
\hline$\geq 4$ & 8 & 27 & & 4 & 31 & & 11 & 24 & \\
\hline \multicolumn{10}{|c|}{ Depth of primary tumor invasion } \\
\hline $\mathrm{T} 1+\mathrm{T} 2$ & 12 & 9 & 0.012 & 8 & 13 & 0.008 & 5 & 16 & 0.188 \\
\hline $\mathrm{T} 3+\mathrm{T} 4$ & 8 & 26 & & 3 & 31 & & 14 & 20 & \\
\hline \multicolumn{10}{|l|}{ Tumor location } \\
\hline Diffuse & 7 & 9 & 0.665 & 4 & 12 & & 5 & 11 & 0.865 \\
\hline Mixed & 7 & 8 & & 3 & 12 & & 6 & 9 & \\
\hline Undetermined & 8 & 16 & & 4 & 20 & & 8 & 16 & \\
\hline \multicolumn{10}{|c|}{ Status of lymph node metastasis } \\
\hline Negative & 11 & 9 & 0.030 & 6 & 14 & 0.161 & 11 & 9 & 0.016 \\
\hline Positive & 9 & 26 & & 5 & 30 & & 8 & 27 & \\
\hline \multicolumn{10}{|l|}{ TNM stage } \\
\hline I & 8 & 8 & 0.944 & 3 & 13 & 0.963 & 5 & 11 & 0.623 \\
\hline II & 7 & 5 & & 2 & 10 & & 4 & 8 & \\
\hline III & 6 & 6 & & 3 & 9 & & 6 & 6 & \\
\hline IV & 7 & 8 & & 3 & 12 & & 4 & 11 & \\
\hline
\end{tabular}

\section{Correlation between protein HIF-2 $\alpha$ and MMP-9/VEGF expression}

Spearman's correlation analysis revealed that the expression of HIF- $2 \alpha$ was positively associated with that of MMP-9 and VEGF in gastric cancer $(r=0.238, \mathrm{P}=0.036 ; r=0.484$, $\mathrm{P}=0.000$; Table 4). 


\begin{tabular}{|c|c|c|c|c|c|c|c|c|}
\hline HIF- $2 \alpha$ & MMP-9 & $\mathrm{N}(\%)$ & $r$ & $\mathrm{P}$ & VEGF & $\mathrm{N}(\%)$ & $r$ & $P$ \\
\hline \multicolumn{9}{|c|}{$\overline{\text { Co-expression pattern }}$} \\
\hline Negative & Negative & $7(12.7)$ & 0.238 & 0.036 & Negative & $13(23.6)$ & 0.484 & 0.000 \\
\hline Negative & Positive & $13(23.6)$ & & & Positive & $7(12.7)$ & & \\
\hline Positive & Negative & $4(7.3)$ & & & Negative & $6(10.9)$ & & \\
\hline Positive & Positive & $31(56.4)$ & & & Positive & $29(52.7)$ & & \\
\hline
\end{tabular}

\section{DISCUSSION}

Recently, molecular markers have been examined for prognostic prediction in gastric cancer patients after curative resection. Although various studies have suggested that several molecular markers should be considered as key prognostic indicators in gastric cancer, no markers are considered to be unified standards in clinical practice (Taylor, 2008; Leonard et al., 2008; Bertout et al., 2009). Overexpression of HIFs is thought to be correlated with cancer progression. However, the role of HIF-2 $\alpha$ in regulating the expression of HIF target genes, such as tumor metastasis-related genes and $V E G F$, in gastric cancer under hypoxic conditions remains unclear. HIF- $2 \alpha$ accumulates in the presence of hypoxia, forms a heterodimer with HIF-1 $\beta$, and binds to hypoxia-responsive elements. HIF- $2 \alpha$ has been shown to regulate a number of the same hypoxia-inducible genes as HIF-1 $\alpha$. However, hypoxia-inducible genes vary in their sensitivity to HIF- $1 \alpha$ and HIF- $2 \alpha$ and therefore different downstream pathways can be preferentially activated. In the present study, we investigated HIF- $2 \alpha$ expression as well as its relationship with MMP-9 and VEGF expression in gastric cancer. The resulting data provide new clues for understanding the molecular mechanisms of the HIF-2 $\alpha$ pathway in gastric cancer development.

The HIF- $2 \alpha$ expression data showed that HIF- $2 \alpha$ mRNA and protein were overexpressed in gastric cancer tissues compared to normal gastric tissues. This result agreed with previous studies showing that HIF-2 $\alpha$ was overexpressed in cancers, as assessed by immunochemical histological analysis, including those of the brain, bladder, breast, colon, ovary, pancreas, kidney, and prostate (Rankin et al., 2007, 2009). Furthermore, HIF-2 $\alpha$ overexpression was significantly correlated with highly aggressive disease and poor prognosis in some cancer types, including breast, ovarian, oligodendroglioma, and oropharyngeal cancers. The HIF-2 $\alpha$ pathway is thought to play an important role in gastric carcinogenesis. HIF-2 $\alpha$ expression has also been suggested to be critical in the carcinogenesis of renal cortical tumors, ovarian cancer, breast cancer, and lung cancers.

Furthermore, this study showed that increasing HIF-2 $\alpha$ and MMP-9 expressions were important in tumor invasiveness and correlated with primary tumor size, in accordance with a previous study (Zhu et al., 2010). When cultured under hypoxic conditions, breast cancer cells showed increased secretion of another gelatinase, MMP-9 (Copple et al., 2010). Hypoxia upregulated MMP-2 and MMP-9 activity in a variety of adenocarcinoma cell lines and increased their invasiveness in vitro (Jiang et al., 2003). To achieve metastasis, a tumor cell must disrupt cell-cell and cell-extracellular matrix contacts, migrate through stromal tissue, invade the basement membrane, and enter/exit the blood stream. These steps are accomplished primarily through the activity of the MMP family of enzymes. Elevated levels of MMPs have been correlated with the invasiveness of several human cancers, as well as with other tumor phenotypes such as angiogenesis, cell proliferation, and resistance to apoptosis. This sug- 
gests that hypoxia can upregulate MMP-9 and enhance cancer cell invasiveness. HIF-2 $\alpha$ may play a role in identifying a patient subgroup that may show a more unfavorable outcome, thus enabling substage-oriented tailored therapy with more intensive treatment and more strict follow-up surveillance.

In this study, our data also indicated that increased HIF-2 $\alpha$ and VEGF expression are important in tumor lymph node involvement. Tumor angiogenesis and neovascularization require VEGF expression and the binding of HIF- $1 \alpha$ to the $V E G F$ promoter, which is a major pathway resulting in the induction of $V E G F$ expression under hypoxic conditions (Choi et al., 2010). Interestingly, HIF-2 $\alpha$ cannot enhance the expression of VEGF in response to hypoxia in gastric cancer. These results indicate that the role of HIF-2 $\alpha$ in the angiogenesis of human gastric cancer may be very complicated. Therefore, we performed an array of in vitro experiments to define the relationship between HIF-2 $\alpha$ and VEGF in the angiogenesis of gastric cancer. Based on the major role of HIFs, MMP-9, and VEGF expression levels in gastric cancer progression (Taylor, 2008; Leonard et al., 2008; Bertout et al., 2009), our study indicates that HIF-2 $\alpha$ may be a critical factor promoting tumor aggressiveness in response to hypoxia by mediating the activation of MMP-9 and VEGF in a subset of gastric cancer patients.

Our results strongly indicate that, at least in gastric cancer, HIF- $2 \alpha$ plays crucial roles in tumor carcinogenesis and progression. Thus, under hypoxic conditions, HIF-2 $\alpha$ in nucleus forms a heterodimer that binds to an enhancer element known as the hypoxia response element in target genes involved in MMP-9 and angiogenesis to regulate the expression of these genes. The results of the present study demonstrate that HIF- $2 \alpha$ enhances the expression of MMP-9 and VEGF in response to hypoxia in gastric cancer. These data offer important information that may be used for developing therapies that target angiogenesis and invasion using the HIF pathway in gastric cancer.

The molecular mechanism underlying HIF- $2 \alpha$ expression in cancer requires further study (Milovanova et al., 2009). The widespread occurrence of up-regulation of HIF- $2 \alpha$ in common cancers and the involvement of hypoxia pathways in tumor angiogenesis indicate its importance and wide applicability. Effective chemotherapy and radiation targeting HIF-2 $\alpha$ is not well developed (Rankin et al., 2008; Majmundar et al., 2010). Therefore, further studies are required to evaluate the effects of HIF-2-mediated pathways on human tumor carcinogenesis and progression microenvironments.

\section{ACKNOWLEDGMENTS}

Research supported in part by the Natural Science Foundation (\#2011A310005), the Science and Technology Foundation (\#112102310206), and a University Key Teacher grant from the Ministry of Education (\#2012GGJS-136) of Henan Province.

\section{REFERENCES}

Bertout JA, Patel SA, Fryer BH, Durham AC, et al. (2009). Heterozygosity for hypoxia inducible factor 1alpha decreases the incidence of thymic lymphomas in a p53 mutant mouse model. Cancer Res. 69: 3213-3220.

Bohensky J, Terkhorn SP, Freeman TA, Adams CS, et al. (2009). Regulation of autophagy in cartilage: HIF-2 suppresses chondrocyte autophagy. Arthritis Rheum. 60: 1406-1415.

Burrows N, Babur M, Resch J, Williams KJ, et al. (2011). Hypoxia-inducible factor in thyroid carcinoma. J. Thyroid Res. 2011: 762905.

Choi YK, Kim CK, Lee H, Jeoung D, et al. (2010). Carbon monoxide promotes VEGF expression by increasing HIF- 
1alpha protein level via two distinct mechanisms, translational activation and stabilization of HIF-1alpha protein. $J$. Biol. Chem. 285: 32116-32125.

Copple BL, Bai S and Moon JO (2010). Hypoxia-inducible factor-dependent production of profibrotic mediators by hypoxic Kupffer cells. Hepatol. Res. 40: 530-539.

Jiang Y, Zhang W, Kondo K, Klco JM, et al. (2003). Gene expression profiling in a renal cell carcinoma cell line: dissecting VHL and hypoxia-dependent pathways. Mol. Cancer Res. 1: 453-462.

Leonard MO, Howell K, Madden SF, Costello CM, et al. (2008). Hypoxia selectively activates the CREB family of transcription factors in the in vivo lung. Am. J. Respir. Crit. Care Med. 178: 977-983.

Liu W, Xin H, Eckert DT, Brown JA, et al. (2011). Hypoxia and cell cycle regulation of the von Hippel-Lindau tumor suppressor. Oncogene 30: 21-31.

Majmundar AJ, Wong WJ and Simon MC (2010). Hypoxia inducible factors and the response to hypoxic stress. Mol. Cell. 40: 294-309.

Mardilovich K and Shaw LM (2009). Hypoxia regulates insulin receptor substrate-2 expression to promote breast carcinoma cell survival and invasion. Cancer Res. 69: 8894-8901.

Mazumdar J, Hickey MM, Pant DK, Durham AC, et al. (2010). HIF-2alpha deletion promotes Kras-driven lung tumor development. Proc. Natl. Acad. Sci. U. S. A. 107: 14182-14187.

Meade ES, Ma YY and Guller S (2007). Role of hypoxia-inducible transcription factors 1alpha and 2alpha in the regulation of plasminogen activator inhibitor-1 expression in a human trophoblast cell line. Placenta 28: 1012-1019.

Milovanova TN, Bhopale VM, Sorokina EM, Moore JS, et al. (2009). Hyperbaric oxygen stimulates vasculogenic stem cell growth and differentiation in vivo. J. Appl. Physiol. 106: 711-728.

Mole DR, Blancher C, Copley RR, Pollard PJ, et al. (2009). Genome-wide association of hypoxia-inducible factor (HIF)$1 \alpha$ and HIF-2 $\alpha$ DNA binding with expression profiling of hypoxia-inducible transcripts. J. Biol. Chem. 284: 1676716775 .

Rankin EB and Giaccia AJ (2008). The role of hypoxia-inducible factors in tumorigenesis. Cell Death Differ. 15: 678-685.

Rankin EB, Beju MP, Liu Q, Unger TL, et al. (2007). Hypoxia-inducible factor-2 (HIF-2) regulates hepatic erythropoietin in vivo. J. Clin. Invest. 117: 1068-1077.

Rankin EB, Rha J, Unger TL, Wu CH, et al. (2008). Hypoxia-inducible factor-2 regulates vascular tumorigenesis in mice. Oncogene 27: 5354-5358.

Rankin EB, Rha J, Selak MA, Unger TL, et al. (2009). Hypoxia-inducible factor 2 regulates hepatic lipid metabolism. Mol. Cell Biol. 29: 4527-4538.

Taylor CT (2008). Interdependent roles for hypoxia inducible factor and nuclear factor-кB in hypoxic inflammation. $J$. Physiol. 586: 4055-4059.

Trisciuogglio D, Gabellini C, Desidrei M, Ziparo E, et al. (2010). Bcl-2 regulates HIF-1alpha protein stabilization in hypoxic melanoma cells via the molecular chaperone HSP90. PLoS One 5: e11772.

Zhu P, Ning Y, Yao L, Chen M, et al. (2010). The proliferation, apoptosis, invasion of endothelial-like epithelial ovarian cancer cells induced by hypoxia. J. Exp. Clin. Cancer Res. 29: 124. 